\title{
Martin Haspelmath* General linguistics must be based on universals (or non-conventional aspects of language)
}

https://doi.org/10.1515/tl-2021-2002

Received March 29, 2021; accepted April 22, 2021

\begin{abstract}
This paper highlights the importance of the distinction between general linguistics (the study of Human Language) and particular linguistics (the study of individual languages), which is often neglected. The term "theoretical linguistics" is often used as if it entailed general claims. But I note that (unless one studies non-conventional aspects of language, e.g. reaction times in psycholinguistics) one must study universals if one wants to make general claims. These universals can be of the Greenbergian type, based on grammatical descriptions of the speakers' social conventions, or they can be based on the natural-kinds programme, where linguists try to describe mental grammars as made up of universal building blocks of an innate grammar blueprint. The natural-kinds programme is incompatible with Chomsky's claims about Darwin's Problem, but it is indispensable for a general linguistics in the generative tradition. The Greenbergian programme, by contrast, can make use of framework-free descriptions because its comparisons are based on independently defined universal yardsticks.
\end{abstract}

Keywords: general linguistics; generative linguistics; language universals; linguistic typology; theoretical linguistics

\section{Introduction}

In this paper, I address a core foundational aspect of linguistics: the difference between the study of a PARTICULAR LANGUAGE (spoken at a particular time by a particular community) and the study of HuMAN LANGUAGE IN GENERAL. I argue that this distinction is important both for particular linguistics and for general linguistics, and I note that it has often been unduly neglected.

*Corresponding author: Martin Haspelmath, Max Planck Institute for Evolutionary Anthropology, Deutscher Platz 6, 04103 Leipzig, Germany, E-mail: martin_haspelmath@eva.mpg.de 
My basic claim is that general linguistics must be based on the empirical study of language universals, unless we study non-conventional aspects of language, e.g. by observing behaviour in psycholinguistic experiments or slips of the tongue or by making stimulus poverty arguments. At first blush, this may seem like a completely uncontroversial claim: It is obvious that languageparticular phenomena are historically accidental to a large extent and we cannot draw conclusions about Human Language from features that are peculiar to English or Quechua, such as the fact that the word for 'house' is wasi in Quechua and house in English. In Plato's dialogue Cratylus, Hermogenes defends the view that the forms of a language are arbitrary and based on convention, whereas Cratylus claims that they have a natural connection to their denotations. As far as the shapes of words are concerned, Cratylus is obviously wrong, and grammatical patterns, too, are largely languageparticular and simply conventional.

Thus, it is not convincing to claim, for example, that the order of French words is a faithful reflection of general logic (as was done by Antoine de Rivarol in his famous 1784 essay on the universality of the French language), because many other languages have different orders and are no less suited for conveying clear ideas. SVO order is not a general property of Human Language, but a parochial property of French. If one wants to make claims about Human Language, one needs to base them on universals - either absolute universals, such as the fact that all languages can express topics and comments (Krifka 2008) or the fact that all languages have demonstratives (Diessel 2014), or on strong tendencies, such as the fact that the great majority of languages have subject-before-object order (Dryer 2005), or the fact that the great majority of languages have symmetrical vowel systems (Gordon 2016: §3.5).

The reason why I am emphasizing this here is that in recent decades, there has been a strong tendency to base general claims on the study of particular languages, or on a small non-representative set of languages, rather than on language universals. For example, Adger et al. (2009) mostly study Kiowa, and Pesetsky (2013) mostly studies Russian, but works like these of course make very general claims. The methodological background of this approach is not as naive as Antoine de Rivarol's claims about the universality of French, but I will argue that many linguists have not considered all the implications when they claim that their study of one or a few languages can make a contribution to general linguistics.

It appears that the confusion arises to a large extent from the widespread replacement of the older notion of "general linguistics" by the new and vague notion of "theoretical linguistics" (often simply called "linguistic theory"). While general linguistics has an unambiguous meaning (the study of Human 
Language as a capacity of humans, or as a general attribute of the human species), ${ }^{1}$ it is much less clear what is meant by "theoretical linguistics". I think that the widespread equation of "theoretical linguistics" with the general study of language obscures some important distinctions, and that the sources of the divisions between linguists of different research communities would become clearer if the crucial distinction between general linguistics and theoretical linguistics became more widely recognized. I will try to clarify various aspects of theoretical linguistics in $\S 2$, before sketching the history of the terms in $\S 3$.

Then in §4, I formulate the central problem: the general linguistics paradox, i.e. the fact that we want to study Human Language, but all we can observe is utterances of particular languages. I sketch three possible solutions: non-conventional aspects of language, worldwide comparison of languages, and a natural-kinds programme that works with hypothetical innate building blocks of languages. The latter is known to be very problematic for a variety of reasons (and interestingly, it has been abandoned by many generative linguists as an explicit programme), but in §5.2 I argue that there is still no way around it for linguists working with the traditional formal tools of generative grammar. If, on the other hand, one does not want to claim that we are born with a rich innate grammar blueprint, one must accept that each language has its own categories (§5.3). This then leads to language-particular descriptions that are not directly relevant to general linguistics, but they can become relevant through worldwide comparisons that work with independent uniform yardsticks for measurement (comparative concepts).

\section{What is theoretical linguistics?}

Much (or perhaps most) research in linguistics can be classified into one or more of the following three familiar types:
a. DESCRIPTION of particular languages (particular linguistics)
b. COMPARISON of languages (general linguistics)
c. EXPLANATION of general features of Human Language (general linguistics)

This trichotomy mostly applies to structural linguistics (the study of language structures), and I do not claim that it applies to psycholinguistics (see §4.1 below). But it also mostly applies to historical linguistics (where what is described, and

1 I use the unusual spelling "Human Language" (with capitalization) in order to emphasize that this is a distinct phenomenon from the various particular languages that we can observe and study directly. 
often only inferred, is diachronic trajectories, and sometimes earlier unattested states of languages), as well as to sociolinguistics. ${ }^{2}$

The term "theoretical linguistics" is poorly suited to singling out any of these three subtypes of activities, because they are all theoretical in some way: It would be strange to say that the description (or comparison) of particular languages is not theoretical (given the widely recognized impossibility of theory-free description; Dryer 2006), and it would also be strange to say that Greenbergian typological linguistics is not theoretical, given that it has since the beginning (Greenberg 1963) been very much interested in deeper explanations of the cross-linguistic generalizations that were found (e.g. Moravcsik 2011; Schmidtke-Bode et al. 2019).

It seems best to oppose theORETICAL LINGUISTICS to APPLIED LINGUISTICS: People who apply knowledge of languages or linguistics to practical tasks (such as speech therapy, language pedagogy, or automatic language processing) are not unhappy if their work does not come with the prestigious label "theoretical”, because they see their contribution in solving practical or applied problems, not necessarily in furthering theoretical understanding. ${ }^{3}$

In some fields (such as physics), there is a conventional subdivision into theoretical and experimental branches, but in linguistics, this does not seem to be a sensible distinction: People who carry out experiments (in psycholinguistics, and increasingly also in phonology, pragmatics, as well as artificial language learning paradigms) are at the same time theorists. Similarly, it does not make any sense to set up a contrast between descriptive and theoretical linguistics (even though this is a common habit), because theory-free description is not possible (see also §5.3). ${ }^{4}$ In the following I will simply ignore all kinds of applied (non-theoretical) linguistics. Everything I will talk about from now on is theoretical linguistics, but not all of it is general linguistics: descriptive linguistics, though theoretical, is particular linguistics, because one language is described at a time. ${ }^{5}$

2 In historical-comparative linguistics, the particular phenomena are sometimes language families, and thus one could say that historical-comparative linguistics is "more general" than the study of a single language. But here I use general linguistics as referring to properties of language that are not dependent on particular historical entities.

3 The contrast between theory and application (or practice) has a long tradition. Gottfried Wilhelm Leibniz (1646-1716) is often said to have adopted theoria cum praxi as his motto ('theory with practice'). And according to Parry (2020), "it is in Aristotle that we find the basis for something like the modern opposition between epistêmê [understanding] as pure theory and technê [art] as practice."

4 Likewise, it is very difficult to make sense of the contrast between "linguistic theory and typology" that one often finds (e.g. Baker and McCloskey 2007). There cannot be any atheoretical typology (see also this blogpost: https://dlc.hypotheses.org/1915).

5 Another pair of contrasting concepts is "theoretical" versus "empirical". I leave this distinction aside here, because it does not refer to different types of research, but to different aspects of 
As a definition of "theoretical linguistics", I thus propose "the study of language(s) that aims primarily at understanding (or explaining) rather than at practical applications”. Given this definition, one might think that general explanation (1c above) is more theoretical than language-particular description (1a), but the difference is merely a matter of different levels: A theoretical account of a particular language (e.g. a descriptive grammar or a dictionary) explains the behaviour of speakers when they speak this language and is thus no less explanatory than a general theoretical account of Human Language.

But different (groups of) theoretical linguists sometimes seem to pursue rather different goals whose mutual relations are often unclear. I think that we can understand the differences best if we elaborate on the three main types of theoretical linguistics that we saw in $(1 \mathrm{a}-\mathrm{c})$. Each of the types can be regarded as having two subtypes, (a) and (b).

DESCRIPTION OF PARTICULAR LANGUAGES (= particular linguistics)

a. description of the social rule systems

b. description of the mental grammars

COMPARISON OF LANGUAGES (part of general linguistics)

a. empirical universals (generalizations over (2a); e.g. Greenberg 1963)

b. universals imposed by biocognitive constraints (generalizations over (2b))

\section{EXPLANATION OF GENERAL FEATURES OF HuMAn LANGUAGE (general linguistics)}

a. functional-adaptive explanations of empirical universals (as in (3a))

b. biocognitive explanations based on an innate grammar blueprint, consisting of universal building blocks (architectures and features/ categories)

Clearly, what traditional generative linguists have been doing is (2b), (3b), and (4b), whereas many other linguists have been describing languages without making any mentalist claims (2a), have been comparing them without any presupposition of specific innate mechanisms (3a), and have proposed functionaladaptive explanations (4a). But crucially, most linguists would accept that the other subtypes of theoretical linguistics exist: Traditional generativists accept that there is such a thing as social norms (calling them or their products "E-language"), they recognize that one can generalize over languages in the Greenbergian way

research. All of science has both theoretical and empirical aspects, and there is no non-empirical science. (Non-empirical works, such as the present article, are not really part of science, but of meta-science, or philosophy of science.) 
and find intriguing patterns, and they would not rule out the possibility of functional-adaptive explanations, even though they may be more interested in biocognitive explanations (e.g. Jackendoff 2002: §2.5; Newmeyer 1994, 2005).

Likewise, non-generativists recognize the existence of mental grammars (and those of the Cognitive Linguistics community are even primarily interested in these), and they of course recognize that many aspects of our species-specific language capacity (human linguisticality) are biologically determined. ${ }^{6}$ What is probably controversial is the existence of biocognitive universals that can be uncovered by comparing a range of mental grammars, i.e. (3b). But even Holger Diessel, a vocal advocate of cognitive usage-based linguistics, accepts, for example, that demonstratives are universal because of a species-specific ability for communicating joint attention (Diessel 2014). So while some theoretical linguists might downplay several aspects of the entire enterprise in (2)-(4) and concentrate on some parts at the expense of others, the overall picture is widely shared.

What is not widely shared, however, is the ways in which we talk about these distinctions, and I think that this is what often leads to confusion. Linguists do not use the term "general linguistics" very much (any more), let alone "particular linguistics", and there is widespread misunderstanding of what divides the different approaches. Thus, one goal of the present paper is to argue for the reintroduction of the terms general linguistics and particular linguistics. ${ }^{7}$

\section{General linguistics and theoretical linguistics: a brief history of the terms}

The study of Human Language was known as "general linguistics" in the 19th and throughout the first half of the 20th century (Percival 1995), and this term became very well-known through Ferdinand de Saussure's Cours de linguistique générale (1916). ${ }^{8}$ Well into the 20th century, general linguistics was not as prestigious as the

6 Haspelmath (2020a) uses the term linguisticality (on the analogy of musicality) instead of language faculty (or capacity for language), in order to make it clear that there is no controversy here (language faculty has sometimes been used in the sense of a domain-specific biocognitive module, or an innate blueprint for grammar, ideas which are controversial).

7 To make the distinction even more salient, one may use the abbreviated terms g-linguistics and $p$ linguistics. I am not sure whether particular linguistics has been used in English before, but at least in German, Einzelsprachlinguistik 'particular-language linguistics' is an established term, at least in informal usage. Chomsky (1986: 1) mentioned "particular grammar", even in a historical context, so the concept has long been familiar to many linguists.

8 A particularly clear earlier exposition of the notion of general linguistics can be found in Georg Curtius's (1862) inaugural lecture at Leipzig University, on the relation between philology and 
study of particular languages, in particular the study of the individual language histories. Pedersen's (1931) survey of discoveries of linguistics in the 19th century does not mention general linguistics at all and limits itself to enumerating the achievements of historical-comparative linguistics of Indo-European languages. The 19th century saw some important works trying to understand language change in general (Paul 1880; Whitney 1875), but it was only in the 20th century that books dealing with Human Language began to become more prominent (Bloomfield 1933; Sapir 1921; Vendryes 1921; note that these, too, dealt with language change to a very large extent). General linguistics existed, but it was not prominent in this period. Most linguists in Europe and North America studied particular languages and saw themselves as Sanskritists, Latinists, Arabists, etc., and few regarded themselves as general linguists (Ferdinand de Saussure himself was primarily interested in Indo-European historical linguistics and his thinking about Human Language in general served as an aid for his diachronic studies; Joseph 2012). The study of particular languages was sufficient for most linguists, because it was prestigious: Unravelling the histories of the major languages was important for the societies at a time when intellectuals in many countries emphasized national achievements.

After 1945, the nationalist perspective was on the wane. In 1947, Anton Reichling addressed the question "What is general linguistics?" in his inaugural lecture at the University of Amsterdam (Reichling 1949), and his interest in the topic also shaped the new journal Lingua that he co-founded in 1949 with A.W. de Groot. Lingua is one of the oldest journals of general linguistics (its offshoot Glossa still has "general linguistics" in its subtitle). ${ }^{9}$

In the second half of the 20th century, the attitude to general linguistics changed for good, and with it the label for the most prestigious activity in linguistics. Since the 1950s, apparently beginning with Chomsky (1957), the term “theoretical linguistics" became more common, and especially with Lyons's (1968) influential textbook An introduction to theoretical linguistics, the older term

linguistics. He notes that the various regional disciplines (the study of the languages and cultures of Greece, of Ancient Rome, of France, etc.) cross-cut the various general disciplines (general art history, general religious studies, general linguistics, and so on). He also remarks that general linguistics is more advanced than other general disciplines and that it is important for the study of particular languages (Curtius 1862: 7).

9 There was a journal of general linguistics in the 19th century (Friedrich Techmer's Internationale Zeitschrift für Allgemeine Sprachwissenschaft, 1884-1890), but this was almost forgotten in the 20th century (see Koerner 1973). (The journal Language was founded even before Lingua, in 1925, but its mission was originally much broader, and in the first few decades, it mostly published studies on particular languages.) 
"general linguistics" was clearly on its way out. ${ }^{10}$ But this was not a necessary consequence of the generative approach. On the one hand, Chomsky (1957) says very clearly that a linguistic theory may deal with a particular language: ${ }^{11}$

Syntactic investigation of a given language has as its goal the construction of a grammar that can be viewed as a device of some sort for producing the sentences of the language under analysis. (1957: 11)

A grammar of the language L is essentially a theory of L. (1957: 49)

But in the preface, he also says that he is interested in constructing "a formalized general theory of linguistic structure and to explore the foundations of such a theory" (Chomsky 1957: 5). So at the beginning of generative grammar, it was clear that there is both particular theoretical linguistics (e.g. theoretical linguistics of English) and general theoretical linguistics. Despite this, the distinction was basically forgotten in later decades. ${ }^{12}$ Language description is often thought to be less than fully theoretical when it does not make use of a general theory (or "theoretical framework", cf. Haspelmath 2010a), but confines itself to presenting an analysis of a language in its own terms, using its own framework. But as I noted in $\$ 2$, such descriptions are fully theoretical; what they lack is immediate general relevance, not theory.

Since the 1970s, more and more linguists have felt compelled to emphasize that their work is "theoretical", even though it was very largely concerned with the description of a single language and the context made it sufficiently clear that the research had no applied goals. The following titles are characteristic of the 1980s:

Foley, James. 1979. Theoretical morphology of the French verb. (Lingvisticæ Investigationes Supplementa.) Amsterdam/Philadelphia: John Benjamins Publishing Company. 296pp.

Shaw, Patricia A. 1980. Theoretical issues in Dakota phonology and morphology. New York: Garland Publishing.

Zubizarreta, Maria Luisa. 1982. Theoretical implications of subject extraction in Portuguese. The Linguistic Review 2. 79-96.

10 The term general linguistics has survived in the names of acedemic departments and study programmes in Europe and beyond, and is probably more widely used in non-English contexts (Russian obščee jazykoznanie, German allgemeine Linguistik, etc.). But Robins (1964) seems to have been the last prominent English-language book with "general linguistics" in its title.

11 This is also found in more recent textbooks, e.g. "a grammar is a linguist's explicit theory of a speaker's tacit knowledge of their language” (Adger 2003: 11).

12 When the journal Theoretical Linguistics started in 1974, its founder Helmut Schnelle (19322015) characterized its subject matter as "concerned with the development of theories about general aspects of particular languages or of language and its uses in general...” (Schnelle 1974:1). So like Chomsky, Schnelle envisaged language-particular theories as well as general theories. 
Saxon, Leslie. 1986. The syntax of pronouns in Dogrib: Some theoretical consequences. Doctoral dissertation, University of California at San Diego.

It seems that the term "theoretical" in these titles is meant to emphasize that the language-particular studies are relevant to general linguistic theorizing - so the term "theoretical" came to mean "general (theoretical)" by the 1980 s at the latest. The situation has not changed much between then and today, though there is less need to include "theoretical" in paper and book titles nowadays because the idea that language-particular research should make a contribution to our understanding of Human Language is now very widely accepted among theoretical linguists. ${ }^{13}$

However, there is a serious, and widely ignored, problem with the view that language-particular studies can make direct contributions to general linguistics: It presupposes that grammatical systems are constructed from a rich set of innate building blocks of universal grammar, and this is a highly contentious idea. I elaborate on this point in the next section.

\section{Three solutions of the general linguistics paradox}

Even though the current generation of linguists is very much used to the idea that we study particular languages in order to understand Human Language, there is actually something paradoxical about this, what I call the general linguistics paradox.

(5) The general linguistics paradox:

We want to explore and understand the nature of Human Language, but what we can observe directly is particular languages.

13 "Theoretical/general linguistics" is also sometimes used in contrast to psycholinguistics, sociolinguistics, and historical linguistics, but these subfields just consider different aspects of particular languages or of Human Language - there can be general sociolinguistics, there can be general psycholinguistics, and there can be general historical linguistics (the latter is sometimes called diachronic linguistics, or evolutionary linguistics). There is no widely used term for the study of language that is not sociological, psychological or historical, but as noted by David Pesetsky (in a Facebook discussion a few years ago) the term structural linguistics would be perfectly suitable for this kind of language study. (I used the term structural linguistics in this way at the beginning of $\S 2$ above.) 
Of course, from a biological perspective, we may say that when we observe the behaviours of chimpanzees, vervet monkeys and humans, we can see some striking differences in the structure and function of the vocalizations of these species, so in a very coarse-grained fashion, it is perhaps possible to observe Human Language, glossing over the differences between particular languages. People speak, but other animals do not. However, this does not give us much further insight, because "no one speaks FL [faculty of language]: people either speak a specific language or they do not speak at all” (Mendívil-Giró 2019: 2). Thus, linguists normally take a much closer look and study words and sentences with their meanings, almost all of which are different in different languages.

So linguists need a solution for this paradox, and in this section, I briefly describe three solutions. The first corresponds to the part that is in parentheses in the title of this paper, and the other two are different ways in which universals help us understand Human Language.

Crucially, the study of a particular language cannot contribute directly to general linguistics without further assumptions, because a particular language represents historically accidental conventions of a speech community. To be sure, we can say somewhat trivially that everything that occurs in a particular language must be possible in Human Language and thus has general relevance. But we generally want to ask more ambitious questions. The situation is basically the same in other disciplines that study culturally variable behaviours of human populations: The study of the history of Mexico cannot directly contribute to general history, and the study of the economics of China cannot directly contribute to general economics. These disciplines need something else - namely worldwide comparative studies - in order to arrive at general conclusions. ${ }^{14}$ (In the natural sciences, the situation is different, as will be noted in §6.2.)

\subsection{First solution: non-conventional aspects of human language}

The problems that I will highlight in $\S 5$ below do not concern those areas of linguistics where non-conventional behaviours are studied. In particular, general inferences from reaction times in psycholinguistic experiments, from electrophysiological experiments in neuroscience, or from slips of the tongue are not problematic because the aspects of behaviour that are of interest here are not socially learned, i.e. are not conventional. Of course, the differences between

14 Like general linguistics (cf. §4.1), general economics also sometimes makes use of experimental methods, as in the subfield of behavioural economics. 
languages still put limitations on general inferences, and there is now an increasing awareness of the need for cross-linguistic research in psycholinguistics as well (e.g. Bak 2016; Bornkessel-Schlesewsky and Schlesewsky 2009; Jaeger and Norcliffe 2009; Slobin 1985). But even without such awareness, psycholinguistic research can lead us to some general conclusions.

Another non-conventional aspect of language is learnability. It has often been argued that some aspects of grammars cannot be learned on the basis of positive evidence and must therefore be present at birth (this is called the argument from the poverty of the stimulus, e.g. Lasnik and Lidz 2016). For example, it has been claimed that principle C of Chomsky's (1981) binding theory for English cannot be acquired on the basis of positive evidence (i.e. the rule that a pronoun in subject position cannot have the same reference as a full nominal in other positions such as non-subject position, e.g. ${ }^{*}$ She $e_{i}$ thought much about Maria $\left.{ }_{i}\right)$. Such learnability considerations do not depend on historically accidental conventions of particular languages and are therefore a valid solution to the general linguistics paradox. ${ }^{15}$ However, in practice they do not play an important role in linguistics - there are very few specific proposals about characteristics of languages that must be innate because they cannot be acquired without innate prerequisites.

A lot more could be said about non-conventional aspects of linguistic behaviour, but the focus of this paper is on the problems that arise when one limits one’s attention to language structures, or linguistic conventions (see also $§ 6.1$ below on what I mean by conventions). This is why the non-conventional aspects of language are in parentheses in the title of this paper.

\subsection{Second solution: general linguistics through worldwide language comparison}

An obvious way in which one could learn about Human Language in general is by comparing languages worldwide and by finding general tendencies in representative samples of these languages. This is the well-known Greenbergian approach (Croft 2003; Greenberg 1963; Song 2018), and I do not need to say much more about it here, except perhaps for reminding the reader that Greenbergian comparison does not rely on mental grammars, but can be based entirely on the social rules

15 Chomsky (1981: 6) expressed it as follows: "A great deal can be learned about UG [= universal grammar] from the study of a single language, if such study achieves sufficient depth to put forth rules or principles that have explanatory force but are underdetermined by evidence available to the language learner. Then it is reasonable to attribute to UG those aspects of these rules or principles that are uniformly attained but underdetermined by evidence.” (See also Mendívil-Giró 2019 for some recent discussion.) 
(cf. (2a) and (3a) above). Thus, there is no need for a "deep" or "true" analysis, but basically any description that gets the facts right (that is observationally adequate) is sufficient as a basis for comparison (cf. Haspelmath 2004, 2014). The comparative concepts on which the comparisons are based are not the same as the descriptive categories used for describing the languages, so that different languages can be approached non-aprioristically, i.e. with no preconceived idea of what the possible categories might be (Haspelmath 2010b; see also $\S 6.3$ below).

Explanation in the Greenbergian programme is typically of the functionaladaptive type: Cross-linguistic tendencies are explained with reference to the adaptation of language structures to their users' needs. For example, special reflexive pronouns tend to be used when coreference is unexpected to help the hearers establish the correct reference (Comrie 1999; Haspelmath 2008), and word order tends to be consistently right-branching or left-branching because this minimizes constituent recognition domains (Hawkins 2014). ${ }^{16}$

\subsection{Third solution: general linguistics based on a natural- kinds programme for the building blocks of languages}

Finally, we get to a third solution to the general linguistics paradox: We could learn about Human Language by finding the innate building blocks from which all the mentally represented grammars are constructed. This is the principles and parameters programme of Chomsky (1981), most clearly laid out (for a wider audience) by Baker (2001) (see also Baker 2010; Huang and Roberts 2016; and many others). D'Alessandro (2019: 10) observes that if there are such innate building blocks, then

the constraints that are discovered about one language could be used to describe a different language. This, I think, is the key difference between generative grammar and other linguistic enterprises, such as typology: while typologists assume that, say, the existence of whmovement in English cannot tell us anything about Chinese, generativists assume that this isn't the case.

The "innate building blocks" include both architectures (e.g. the distinction between D-structure and S-structure, between syntactic computation and spell-out, between Merge and Agree, between level I and level II, between Gen and Eval in OT) and innate features, categories and constraints (e.g. $\pm \mathrm{N}, \pm \mathrm{V}, \mathrm{vP}, \mathrm{CP}, \mathrm{SUBJ}, \mathrm{OBJ}$,

16 I use the term "functional-adaptive explanation" to emphasize that the level of the explanation is the cultural evolution of human languages in general, not a correspondence between particular functions of a language and particular forms. 
$+\mathrm{WH}, \pm$ coronal, NoCoda). There is a very rich literature with proposals about the kinds of entities that might be innate building blocks of this kind, which are thought to be part of universal grammar. Chomsky (1965) called the architectural building blocks "formal universals", and the features and categories "substantive universals" (there were no OT constraints in the 1960s, but these would surely also fall under substantive universals).

As noted by Baker (2001), this research programme is not unlike the programme pursued for chemistry in the 19th century that resulted in Mendeleyev's Periodic Table of Elements. Theoretical chemists found that all chemical compounds are built from about 80 to 100 building blocks, and that there are a limited number of ways in which these can combine to form chemical compounds.

If linguists found that there are just a few dozen (or maybe a few hundred) features or categories (or OT constraints) that recur across languages and from which more complex structures can be constructed in a limited number of ways, then it would indeed be plausible to attribute them to the innate universal grammar, and they might also solve the problem of language acquisition despite the poverty of the stimulus (called “Plato's Problem” by Chomsky 1986).

I call this the NATURAL-KINDS PROGRAMME (or naturalistic programme) for general linguistics, ${ }^{17}$ because chemical elements are the primary example of what are called natural kinds in philosophy. ${ }^{18}$ Natural kinds are categories or classes of entities that exist in nature independently of any scientific observation. The categories are given in advance of observations, and are thus available a priori. In addition to chemical elements, examples of natural kinds are particles in physics, and (more controversially) species in biology. Clearly, some aspects of human behaviour and cognition are given by nature, e.g. the fact that we can distinguish five basic tastes (sweet, sour, salty, bitter, umami), and maybe that there are six basic emotions (anger, disgust, fear, happiness, sadness, surprise; see Barrett 2006). So it is readily conceivable that our biology might give us four basic parts of speech (e.g. noun, verb, adjective, preposition), or three components of grammar (e.g. phonology, morphology, syntax), or 27 distinctive features for spoken phonology, or 65 semantic primitives (see also Aronoff 2016). There could also be hundreds of different optimality-theoretic constraints, just as there are hundreds of different cell types in the human body. For phonology, linguists are fairly close

17 Another term is the more colourful expression "Mendeleyevian Vision", which also expresses the fact that so far, no widely accepted results of this programme exist, so that it remains a vision for the time being. (And since Baker $(2001,2010)$ is a prominent proponent of this programme, it can also be called "Bakerian programme".)

18 Noam Chomsky has repeatedly called for a "naturalistic approach" to the study of human language (e.g. Chomsky 1995), which seems to mean more or less what I mean here by naturalkinds programme. 
to a consensus of what the innate features might be, as can be seen in any phonology textbook (though even in phonology, there are dissenting voices of linguists who do not think that the features are universal and innate, e.g. Mielke 2008). In morphology and syntax, there is no such consensus, but it could still be that the search will ultimately be successful.

However, there is a serious problem: In contrast to the Greenbergian programme for cross-linguistic comparison, the natural-kinds programme has no clear methodology for progressing, and no clear criteria for success. ${ }^{19}$ There are a large number of new proposals about the building blocks of the innate grammar blueprint, but there is little (if any) convergence among them. There is no agreement about serial versus parallel architectures, lexicalism, DP versus NP, antisymmetry, phases, cartography, and many other core aspects of grammar. Those new ideas and generalizations that have been widely accepted belong to the level of phenomena (D’Alessandro's 2019 “mid-level generalizations”), not the explanatory level of innate natural kinds. And of course, the existence of a large number of domain-specific innate elements in just one species is inherently unlikely, given the relative recency of our capacity for language (perhaps only 200,000 years old). Moreover, in the 21st century, the natural-kinds programme has basically been given up by some influential authors, as I will briefly note in $\S 5.1$.

This leads me to the last section of this paper - the question whether it is possible to do general linguistics without large-scale cross-linguistic comparison and without a natural-kinds programme. I will end up with a very skeptical answer, resulting in the claim of the title of this paper: General linguistics must be based on universals.

\section{How can general linguistics be based on particular languages?}

Many linguists study primarily conventional aspects of languages (i.e. they are not psycholinguists), but they still want to contribute to general linguistics. We saw that this is possible by comparing languages worldwide and providing functionaladaptive explanations (§4.2), or by finding the universal building blocks from

19 Huang and Roberts (2016) still advocate the principles and parameters programme, but they recognize that the original conception from the 1980s (based on macroparameters) was not really successful. The examples that they give (the head parameter, the null subject parameter, the whmovement parameter, the non-configurationality parameter, the polysynthesis parameter, and a few others) have been largely abandoned by generative syntacticians. 
which all grammatical systems are constructed (§4.3). But few linguists study many languages in a worldwide perspective, and over the last two decades, not many linguists have explicitly advocated (let alone actively pursued) the Bakerian natural-kinds programme. The current section highlights these contradictions, leading to the conclusion (in \$7) that the general linguistics paradox can only be resolved by establishing a coherent comparative methodology (of the nonaprioristic kind or of the natural-kinds type), and by embedding research on particular languages in such a methodology. General linguistics must be based on universals.

\subsection{The 21st century shift}

What I described as the natural-kinds programme (§4.3) was developed in the last few decades of the 20th century, and it was widely adopted, also by linguists who did not agree with Chomsky's particular proposals for syntactic building blocks in the 1970s and 1980s. Syntactic frameworks such as Relational Grammar (Blake 1990) and Lexical-Functional Grammar (Bresnan 2001) saw themselves as making use of universal innate building blocks as well, and the situation in phonology and morphology has been rather similar. A widespread view has been that linguists should try to find a descriptive framework that allows us to describe all languages, but is at the same time restrictive enough to explain language acquisition and the limits on worldwide linguistic diversity (this describes what I called the RESTRICTIVIST APPROACH in Haspelmath 2014).

But since Hauser et al. (2002) and Chomsky (2005), this programme has been basically abandoned by many linguists as an explicit goal. The 21st century Chomskyan idea is that the innate universal grammar contains only rather minimal building blocks, perhaps only the operation Merge, which explains that languages can have recursion. In Chomsky et al. (2019: 230), the authors even say that "universal grammar" is merely the label for whatever biocognitive differences there are between humans and other animals. One of the motivations for this much less ambitious view of what is innate seems to be that a rich set of innate building blocks has come to be seen as implausible from the perspective of biological evolution (and thus the abandonment of a rich UG would help solve "Darwin's Problem"; cf. Berwick and Chomsky 2016).

So on this view of Human Language, there is no substantial natural-kinds programme anymore. The general theory is no longer restrictive and cannot explain observed limits on cross-linguistic variation, because with Merge alone, a large number of unattested grammars are possible. Now what does this mean for the practice of the linguist who studies the structures of particular languages? It 
would seem to me that a necessary consequence is that descriptions of particular languages are no longer carried out in terms of a set of universal building blocks in other words, description can and should be non-aprioristic, or framework-free (Haspelmath 2010a; see §5.3). ${ }^{20}$ But this is not what has generally happened, as I note in the next subsection.

\subsection{The implicit continuation of the natural-kinds programme}

Even though the idea of a rich innate blueprint for grammars was given up by influential authors ( $\$ 5.1$, this is not reflected in the practice of mainstream generative grammar. Journals such as Linguistic Inquiry, Syntax and Glossa continue to publish many papers on particular languages that work with a highly technical metalanguage for describing/analysing the morphosyntactic phenomena of languages. It is quite common for research articles to consist of two parts: One part lays out the phenomena in a way that is generally comprehensible to any linguist, and another part (typically called "analysis") describes the phenomena a second time, using the highly technical metalanguage of current mainstream generative grammar (or more rarely, of some other generative approach, such as Distributed Morphology or Lexical Functional Grammar).

For example, Welch (2016) first describes various conditions for the use of copulas in Dogrib (a Dene language) in a generally accessible way, and then in his $\S 6$ ("Analysis") describes the same facts using technical generative vocabulary such as “merge”, “AspP”, and “ $\varphi$-agreement”. And Holmberg et al. (2019) describe a generalization about the interaction of question formation and passivization in ditransitives in some Germanic and some Bantu languages, and then in their $\S 3$ ("Analysis") describe the same facts again using technical vocabulary such as "phase”, “specifier” and "ApplP”. Anyone who has a certain amount of experience in this field will confirm that this is very typical: Studies of particular languages make use of highly specific concepts that are thought to be universally applicable.

How does this approach contribute to general linguistics? Clearly, these authors build on the assumption of a rich innate grammar blueprint, because otherwise there would be no reason to have the "analysis" section in addition to the generally comprehensible description of the phenomena in the first part of their papers. The "analysis" adds something, because it redescribes the same facts

20 By "framework-free" (Haspelmath 2010a), I mean that there is no universal descriptive framework for all languages. Of course, one needs general concepts for describing a language (just as for describing anything else), and these could be called "framework" - but there can be a different framework for each language. 
by means of a universal vocabulary of innate building blocks. This is not redundant because it embodies the claim that these descriptions capture the mental grammars of the speakers, and these mental grammars are instantiations of the innate grammar blueprint. By studying a wide range of mental grammars in this way, we can hope to get closer to the true innate building blocks that underlie all human languages and thus get insight into Human Language. This is formulated by Huang and Roberts (2016: $§ 14.2)$ as follows:

The P\&P model is a very powerful model of both linguistic diversity and language universals. More specifically, it provides a solution to Plato's Problem, the logical problem of language acquisition, in that the otherwise formidable task of language acquisition is reduced to a matter of parameter-setting. Moreover, it makes predictions about language typology: parameters make predictions about (possible) language types, as we will see in more detail [below]. Furthermore, it sets the agenda for research on language change, in that syntactic change can be seen as parameter change ... Finally, it draws research on different languages together as part of a general enterprise of discovering the precise nature of UG: we can discover properties of the English grammatical system (a particular set of parameter values) by investigating Chinese (or any other language), without knowing a word of English at all (and vice versa, of course).

So despite the fact that the natural-kinds programme has generated few generally accepted results (as noted by authors such as Newmeyer 2005 and Boeckx 2014, and as admitted by Baker 2008), these authors continue to pursue this idea, and they are not alone.

Regardless of how promising it may be to look for innate building blocks, this is a coherent position (cf. also Dryer 2016: 314). But many other generative linguists are adopting what appears to be an incoherent stance: They work with the technical vocabulary and rule notation of mainstream generative grammar which is supposed to apply to all languages, but at the same time, they do not endorse the natural-kinds programme of an innate grammar blueprint. This view is articulated, for example, by Koeneman and Zeijlstra in a blogpost (https://dlc.hypotheses.org/ 1082), where they explain the choices made in their (2017) syntax textbook:

although we build up the theory using technicalities that are adopted from current minimalism, we do not adhere to or to try to persuade students about most of its philosophical or biological underpinnings, such as innateness claims or conjectures about the biological function of language

It seems that they think of their complex formal apparatus (which can account for only a very small part of English grammar) as somehow merely a notation, but they do not discuss alternative notations, of which there are many different ones that are much simpler and would be able to describe a much larger part of English. So one can make sense of what they actually do only if they adopt the traditional 
(20th century) view of the notation of generative grammar as a theoretical claim about a rich innate grammar blueprint. ${ }^{21}$

Even though many linguists have nominally abandoned the idea of an innate grammar blueprint, it apparently got entrenched in linguistics to such an extent that we do not think much about it. We propose categories, architectures and formalisms that can be applied to all languages without thinking much about the reason for their possible generality. As a final example, let us consider the following opening paragraph of a paper about Russian Nominalization constructions (Smirnova and Jackendoff 2017: 877):

Despite the fact that the analysis of nominals has for a long time received a certain amount of attention (e.g. Chomsky 1970; Grimshaw 1990), argument realization and case assignment in the nominal domain have been primarily viewed through the lens of verbal syntax. Here we analyze nominals on their own terms, proposing a lexicalist, constraint-based approach to case assignment in Russian nominals, couched within the simpler syntax framework (Culicover and Jackendoff 2005).

Smirnova and Jackendoff only discuss Russian, and they simply presuppose that a discussion of Russian Nominalizations must be relevant to the English phenomena discussed earlier by Chomsky and Grimshaw, which is clearly the case only if "nominalization" is somehow part of the innate grammar blueprint. If it were not, then it could be that Russian is entirely irrelevant to understanding English. Or it could be that it is only historically relevant, because the similarities are due to a shared history (either inheritance or borrowing via French). Since there is no consensus about these matters in the discipline, the authors would have to spell out their assumptions in terms of natural kinds in order to be understood also by linguists who do not share these assumptions. The reviewers of the journal apparently did not deem this necessary, apparently because the traditional (20th century) generative position is still an implicit default position. ${ }^{22}$

So the answer to the question at the beginning of this section is: General linguistics can be based on a single language if one adopts the natural-kinds

21 See also this blogpost for further discussion: https://dlc.hypotheses.org/1392.

22 Likewise, it is telling that the expression "linguistic theory" is routinely used for the naturalkinds approach, apparently without recognizing that this approach is just one of several rather different ways of pursuing theoretical questions in linguistics. A typical example is the following passage from Larson (2010: 365): “On the one hand, linguistic theory must be capable of describing accurately and adequately all of the world's languages... On the other hand, all natural languages must be acquired by children, presumably from a developmental starting point that is constant across the species. Another task of linguistic theory is to explain how this is possible." If one makes different assumptions about the likelihood of a rich innate grammar blueprint, the theoretical questions are of a completely different sort. 
programme, but not otherwise. The "Mendeleyevian" or "Bakerian" approach (§4.3) thus remains the only coherent way in which one can do general linguistics if one wants to adopt a universal framework. But let us now see how the frameworkfree approach solves its own challenges in view of the general linguistics paradox.

\subsection{Framework-free descriptive linguistics}

While generative linguists who study a single language cannot contribute to general linguistics without subscribing to a natural-kinds programme of some kind, the situation is quite different for linguists who are happy to describe each language in its own terms, in the Boasian tradition. They need not endorse an inherently unlikely proposal about an innate grammar blueprint, but their work does not automatically contribute to general linguistics. Their work is particulartheoretical, not general-theoretical (cf. §2). As noted by D’Alessandro (2019) (in the quotation in $\S 4.3$ above), a Boasian/Greenbergian linguist cannot use phenomena from one language for the description of another.

Perhaps surprisingly, this mode of language description has been advocated by a number of prominent typologists (Cristofaro 2009; Croft 2001; Dryer 1997; Haspelmath 2018; Lazard 2005; Levinson and Evans 2010), but how is it compatible with cross-linguistic comparison? How can it be reconciled with the idea that language descriptions should contribute to an understanding of Human Language through the discovery of universals? After all, experience shows that grammatical descriptions are easier to understand and more relevant to general readers if they are written with the needs of comparativists in mind. Evans and Dench (2006: 5) put it like this:

Describing each language entirely on its own terms is a noble and galvanizing task, but unless grammarians orient their findings to what typologists know about the world's other languages, their grammars can all too easily become obscure, crabbed and solipsistic.

The tension between a kind of description that is faithful to the categories of each language and a description that makes the language appear relevant to general concerns is just a special case of the "general linguistics paradox" that we saw earlier in (5). The solution must consist of two parts.

First, language description is true to the categories of each language, but is inspired by the accumulated knowledge of comparative linguistics (Haspelmath 2020b: §4). So if there is an affix on the verb that is very similar to an applicative or an evidential, it should be given this label, rather than some other idiosyncratic label. But at the same time, it cannot be assumed that what we know about other languages (or about Human Language) determines the language-particular 
analysis. Language-particular analysis is determined by the facts of each language, not by other languages or by a general theory.

Second, comparison of languages is not expected to be based on the categories of the particular languages, because there is no uniform set of building blocks of which all grammatical systems are composed. Thus, the building blocks themselves cannot be the basis of comparison, but we must use independent yardsticks for comparative "measurement" (cf. Haspelmath 2019: §8 on measurement uniformity vs. building-block uniformity). I will elaborate on this in $\S 6.4$.

Thus, grammatical descriptions can contribute to general linguistics in an indirect way: By providing crucial data for large-scale cross-linguistic comparisons, which in turn can tell us about Human Language if we find strong cross-linguistic universals (as noted in §4.2).

\section{Frequently asked questions}

Even before the published peer commentary, I received quite a few comments from colleagues (also from reviewers for another journal, Glossa), so here I add a few subsections on issues that came up repeatedly. They are not crucial to the main points of my paper, which will be summarized in the concluding section (§7).

\subsection{What exactly are conventional aspects of language?}

One colleague objected that it is odd to say that comparative grammar in the Greenbergian tradition is based on "social conventions", and that reaction time experiments involve "non-conventional aspects of language”. And indeed, linguists do not often talk like this, because there is a strong mentalist bias in the field. We talk about acceptability judgements as if they involved "introspection" into our mental grammars, whereas what we actually do is assess the social acceptability of a possible sentence (in terms of linguistic norms). While it is of course true that our knowledge of the social conventions must be mentally represented, the conventions themselves are "social facts", and when we describe a language, we describe it as a social rule system. This is particularly clear in the case of child multilingualism, where one of the tasks that the child faces is to link sets of linguistic conventions to sets of social situations. And since all languages have different registers, monolinguals are not in a very different situation. Thus, all grammatical regularities and all the words and meanings of a language are its conventional aspects. The two main sources of data for studying conventional aspects of language are corpora and elicitation (including self-elicitation). Until a few decades 
ago, virtually all of linguistics consisted in the study of linguistic conventions, or language structures.

In striking contrast to this, when we observe a child's first attempts to talk, or an aphasic's speech, or a slip of the tongue, we do not enter the results into a "child language dictionary", set up an "aphasic's transformational rules”, or posit a "phonemic error system". Language description of the classical sort (resulting in grammars and dictionaries) is not relevant for non-conventional behaviour. And similarly, when we investigate aspects of ordinary language behaviour that plays no social role (such as reaction times, or event-related brain potentials), this is different from conventional behavioural patterns that derive from social learning and that may be considered socially appropriate or not.

These distinctions should be clear enough, but I elaborate on them here because linguists do not yet have terms for structural linguistics (the study of conventional patterns) and non-structural linguistics (the study of other kinds of linguistic behaviours) that are widely understood. It also needs to be noted that the explanatory factors that are invoked are not necessarily conventional aspects of language. The innate building blocks of traditional generative linguistics are not conventional, but they are claimed to constrain the kinds of conventions that people can acquire. In the non-aprioristic approach, each language has its own building blocks, and these elements are themselves conventional.

\subsection{Aren't there analogous "paradoxes" in other disciplines?}

Regarding the "general linguistics paradox" of $\S 4$, one colleague objected that they do not see "how this is any more of a paradox than scientists in other fields face". For example, biologists want to explore and understand the nature of bat echolocation or crab locomotion, and what they can observe directly is only particular bats or crabs.

But how is it that biologists can generalize from a single bat to all members of the species? If species are natural kinds (as I said in Haspelmath 2018: 90, admittedly simplifying matters), then the answer is simple: By their nature, all bats and all crabs have the same essential properties, so by studying one specimen, one learns about the entire species. This view of biological species is the basis of taxonomists' practice of attaching scientific names to “types”, i.e. specific specimens kept in a research collection. ${ }^{23}$ This approach is possible because the

23 At least since Ernst Mayr's widely known proposals about essentialist versus population thinking (e.g. Mayr 1959), many biologists have emphasized the population nature of species. Of course, to the extent that species do not share essential features, they are more like languages, and 
properties of different specimens do not vary by historical accident the way that the observable properties of languages vary. The same goes for other disciplines that work with natural kinds such as chemistry and physics, but there are also natural sciences that study their phenomena using comparative concepts just like linguistics (e.g. the study of clouds in meteorology, or the study of topographic features in geomorphology).

\subsection{Why must comparative concepts be different from descriptive categories?}

While language structures are often similar, each language is structurally unique (e.g. Haspelmath 2020b). Phoneme systems carve up the phonetic space in different ways, and semantic systems are often different even in closely related languages (cf. German fahren vs. gehen, which work quite differently from English drive vs. go). Syntactic classes are often strikingly different, as can be seen in the very different behaviour of English auxiliaries and German auxiliaries, in the very different behaviour of Polish person clitics and French person clitics, and the very different classifications of Arabic gender (masculine vs. feminine) and Swedish gender (neuter vs. non-neuter). Perhaps most notoriously, what is meant by the syntactic term "subject" differs from language to language in confusing ways. In English, even an expletive like there can behave as a "subject" (cf. I believe there to be two unicorns in the garage), and in Icelandic, a "subject" can be in Dative case, while this is never so with Latin "subjects". There are usually enough similarities between different languages to make it tempting (and in some sense useful) to reuse the same terms (e.g. "auxiliary" both for English modal auxiliaries and for German tense auxiliaries), but the categories are really defined by their languageparticular structural behaviour (e.g. the lack of non-finite forms of English modal auxiliaries), not by instantiating some general (aprioristic) category.

These differences mean that language systems are incommensurable, so that making them comparable requires extra effort. In most cases, we cannot simply translate from one language to the next by substituting different morphs. The most straightforward way of making languages comparable is by creating comparative concepts to which the structural elements of each language are mapped. For the case of fahren/gehen/drive/go, we can start with the comparative concepts 'go', 'go by car', 'go by vehicle', and 'go by foot'. The simple equation of German fahren with

it is not enough to describe a single specimen. In effect, if we adopt a radical population view of species (as sets of specimens with no essential shared properties) we must study them in the same way as languages, by creating comparative concepts and trying to find universals. 
English drive fails because the latter means 'go by car', whereas fahren is also used for going by bicycle or by train. And while gehen seems to correspond to go, it can actually only be used for going on foot. So while there are clear similarities here, we need extra concepts to describe how the languages are similar or different. The same goes for phonological categories, where we need phonetics-based comparative concepts, and for syntactic categories, where our comparative concepts must be based on a combination of semantic and phonetic concepts. For example, an ergative case marker is a marker that occurs on a nominal expressing a transitive agent but not on a nominal expressing an intransitive agent (this must be based on a clear comparative definition of "(in)transitive”, see Haspelmath 2011).

So comparative concepts are necessarily based on phonetic and semantic substance that is independent of language-particular structural distinctions, while language-particular categories are based on contrasts, not on substance. It has long been recognized, for example, that phonemes are not defined by their phonetic properties, but by their place in the system of oppositions. But we still want to compare phoneme systems, which must be done in terms of the phonetic features of the inventories.

\subsection{How do we decide whether a language-particular category matches a comparative concept?}

One colleague asked how - if there are no innate categories - we can decide on what is a particle, or an adposition, or a subject, or a reflexive pronoun. And I agree with them that "this is the number one problem that needs to be addressed". Indeed, if we want to compare language structures in the world's languages and find universals, we need to have uniform "yardsticks" for comparison, analogous to measurement in other sciences (cf. Round and Corbett (2020) on the "measurement” metaphor). In Greenberg's (1963) pioneering work, this issue was mostly left aside, and Greenberg limited himself to saying that he was employing semantic criteria in identifying phenomena like "subject", "verb" and "genitive construction" (1963: 59).

The issue of cross-linguistic comparability was not widely discussed until Dryer (1997) and Croft (2001) pointed out that language-particular categories are defined by language-particular criteria and thus cannot be compared directly. Since Haspelmath (2010b), the idea of defining comparative terms carefully in such a way that they can be applied to all languages uniformly has been steadily gaining ground. If a category were innate and thus given a priori, it would be reasonable to think that it is identified by different criteria in different languages, but if not, we 
need to provide definitions that focus on phonetic and semantic substance and make no reference to language-particular structures.

For example, an adpossessive construction (Greenberg's term was "genitive construction") is defined as a nominal with a possessed noun and an adpossessor nominal or person index where the possessor referent is in an ownership, kinship, or part-whole relation to the referent of the possessed noun (e.g. KoptjevskajaTamm 2001). This fairly complex definition presupposes other terms that are themselves not straightforward (noun, nominal, person index) and that need to be defined carefully in turn. At each stage, it must be ensured that the definitions do not contain concepts that cannot be applied to all languages uniformly. For example, as noted in Haspelmath (2008: 43), the binding conditions of Chomsky (1981) cannot be tested in languages worldwide with a measurement approach because there are no generally applicable definitions of terms like "anaphor" and "pronominal", and concepts like "c-command" presuppose specific analyses, which cannot be arrived at in an objective manner. For Chomsky's approach at the time, this was not a problem, because he assumed that his notions were innate building blocks, so they did not have to be defined in such a way that the definition can be applied to all languages uniformly (and it becomes possible to use different criteria for different languages; Haspelmath 2018: §7). But for the Greenbergian approach, the requirements are different, because language comparison is based on uniform measurements of grammatical patterns (cf. 3a), not on true analyses of mental grammars (cf. 2b). The descriptive meta-language is not assumed to be an innate framework, so it cannot simultaneously serve for cross-linguistic comparison and for explanation (Bickel 2015: §2).

\subsection{What is a "rich universal grammar", and why is "richness" relevant?}

In the earlier sections I have repeatedly talked about a "rich set of innate building blocks”, or a "rich UG”, but why should this be relevant here? Isn't it an empirical question how rich our innate knowledge of grammar is?

The reason this is relevant is that de facto, many linguists assume a very rich set of innate building blocks, because each time they use a category that was motivated for one language for another one, this category must be innate. For example, as D’Alessandro (2019) notes (in the quotation of §4.3), wh-movement in English is thought to be informative for Chinese, because a notion such as "question pronoun", as well as a notion such as "movement", is thought to be innately given. And the same applies to many other building blocks (CP, \pm coronal, anaphor, AUX, specifier, and so on) which are routinely made use of in technical 
analyses (for example, Welch (2016) uses notions like AspP, Asp', TP, spell-out, [PERSON], which must be assumed to be innate).

As noted earlier ( $\$ 5.1$ ), some influential authors have suggested that perhaps much less is innate than has traditionally been thought, and it has specifically been suggested that substantive features are not innate (e.g. Hornstein 2018). This is what I would call "minimal UG", and the more minimal it is, the more it is compatible with (or even indistinguishable from) the Boasian/Greenbergian approach (as I noted in §2, everyone accepts the existence of biocognitive prerequisites for language). For this reason, it is not sufficient to contrast "UG" versus "non-UG" approaches. It is specifically the rich-UG approach of Chomsky (1981), Baker (2001), and Huang and Roberts (2016) that allows one to combine p-linguistics with g-linguistics, and that can be seen as a competitor of the Greenbergian approach. ${ }^{24}$

In $§ 5.1$, I also said that the 21st century minimalist view of what is innate is "less ambitious" than the traditional generative approach, and I was asked by a colleague whether it wasn't the other way round: "It is more ambitious to assume fewer innate constraints and still derive the same results." Now that would certainly be the case, but de facto, leading 21st century generativists have largely given up on the Bakerian parametric programme (cf. Boeckx 2014). They do not derive the same results that authors like Roberts, Cinque and Baker hoped to derive from innate parameters and principles. A lot of 21st century work has been studying particular languages (e.g. Adger et al. 2009; Holmberg et al. 2019; Pesetsky 2013; Welch 2016), but the kinds of explanatorily ambitious proposals that were characteristic of the 1980s and 1990s seem to be largely absent. Thus, by eliminating "richness" of UG, generative grammarians have also tended to reduce the explanatory scope of their analyses. There is no clear contribution to general linguistics in this kind of work.

\subsection{Top-down versus bottom-up styles}

Several colleagues have mentioned that there is a contrast between a top-down and a bottom-up style of comparative research. One may either generate a highly

24 It is true, as one colleague observed, that if UG is "too rich", it will likewise allow almost any language, just like a UG that is impoverished. This can be seen in Optimality Theory, where many authors posited very specific constraints, thus reducing the restrictiveness of the approach. The challenge of the Bakerian programme is to have a set of innate building blocks that allows just those languages that are actually attested. Like the "impoverished-UG" approach, such a "superrich-UG" approach is hard to distinguish from the non-aprioristic approach (and indeed, some OT phonologists have basically become functionalists, e.g. Hayes et al. 2004). 
general hypothesis and then look for confirming or disconfirming evidence, or one may start in a bottom-up way with a survey of the phenomena. In practice, most comparative work represents a mixture of these styles, but it is indeed the case that some linguists spend more energy on top-down proposals, while others spend more energy on bottom-up research. This contrast has also sometimes been called "deductive" versus "inductive", and some people may want to describe it as "theoretical" versus "empirical" (see note 5). For example, the book series Empirical Approaches to Language Typology (De Gruyter, 65 volumes since 1987) presumably intends "empirical" in the bottom-up sense. This represents a different dimension from the "theoretical-applied" dimension that I focus on in this paper, and crucially, it is not relevant to language-particular analyses (the kind of research that the vast majority of linguists are concerned with). P-linguistics is not more or less "theoretical" or "empirical"; it is only more or less "general" (either focussing on general implications, or leaving these aside).

\section{Conclusion}

To conclude, let me reiterate the three main points of this paper:

First, there is an important distinction between general and theoretical linguistics (§2). The non-applied study of a particular language ("descriptive linguistics") is no less theoretical than the study of Human Language. And it is not immediately clear how one could learn about Human Language in general by studying a particular language (\$4). Particular languages are to a large extent historically accidental cultural attributes of human populations, and they vary enormously just like other aspects of cultures. This problem is what I called "the general linguistics paradox".

Second, there are two ways in which one can solve this paradox (if we leave aside the study of non-conventional aspects of language and language use): One can apply a hypothesized set of innate building blocks to particular languages (the "natural-kinds programme"), or one can study a wide range of languages on the basis of uniform yardsticks of comparison. The former is associated with Chomsky's traditional generative grammar ideas between the 1960s and 1980s, and the latter became prominent with Greenberg's work of the 1960s and 1970s (§4.2-3).

And third, I pointed out that while ordinary working linguists most typically study particular languages, particular linguistics ("p-linguistics”) no longer has the prestige that it had in the 19th and early 20th century, so there is a strong incentive to make one's work relevant to general linguistics. But this is confronted with difficulties: For the natural-kinds approach, the difficulty lies in the fact that 
this programme was given up by some leading authors in the 21st century (\$5.1). And for the Greenbergian approach, the difficulty lies in the fact that worldwide comparison of languages has revealed a great diversity of categories, so that the categories of description cannot be used for comparison ( $\$ 5.3)$.

The solution for the natural-kinds approach must thus lie in continuing the search for universal building blocks and for evidence of their innateness, as practiced in the 1980s and the 1990s (e.g. Cinque 1999; Roberts 1997). For the nonaprioristic comparative approach, the solution consists in recognizing that the categories of description are not the same as the yardsticks for comparison, so that language-particular studies contribute to general linguistics only in an indirect way. No linguist can simply pretend that the description of a particular language will automatically contribute to general linguistics.

Thus, whatever one's hunches about the best path leading to deeper understanding of Human Language: All general linguists need a clearer methodology for language comparison. Despite many obvious similarities between languages, they appear to have different categories and features, and we need something extra to make the study of particular languages fruitful for general linguistics.

For linguists working in the generative tradition, this means figuring out which features and categories (and architectures) must be innate and can be expected to occur in any language. For linguists working in the Boasian/Greenbergian tradition, this means being careful about their characterization of comparative concepts as uniform yardsticks for comparison.

If all goes well, the two approaches should eventually converge, i.e. evidence for innateness should converge with the empirical universals found through the non-aprioristic approach.

Acknowledgments: I thank three reviewers for Glossa, as well as Hans-Martin Gärtner for detailed comments on an earlier version. I also had many useful comments on Academia.edu. The support of the European Research Council (ERC Advanced Grant 670985, Grammatical Universals) is gratefully acknowledged.

\section{References}

Adger, David. 2003. Core syntax: A minimalist approach. Oxford: OUP.

Adger, David, Daniel Harbour \& Laurel J. Watkins. 2009. Mirrors and microparameters: Phrase structure beyond free word order. Cambridge: CUP.

Aronoff, Mark. 2016. Unnatural kinds. In Ana R. Luís \& Ricardo Bermúdez-Otero (eds.), The morphome debate, 11-32. Oxford: OUP.

Bak, Thomas H. 2016. Cooking pasta in La Paz: Bilingualism, bias and the replication crisis. Linguistic Approaches to Bilingualism 6(5). 699-717. 
Baker, Mark C. 2001. The atoms of language. New York: Basic Books.

Baker, Mark C. 2008. The macroparameter in a microparametric world. In Theresa Biberauer (ed.), The limits of syntactic variation, 351-373. Amsterdam: Benjamins.

Baker, Mark C. 2010. Formal generative typology. In Bernd Heine \& Heiko Narrog (eds.), The Oxford handbook of linguistic analysis, 285-312. Oxford: OUP.

Baker, Mark C. \& James McCloskey. 2007. On the relationship of typology to theoretical syntax. Linguistic Typology 11. 285-296.

Barrett, Lisa Feldman. 2006. Are emotions natural kinds?. Perspectives on Psychological Science 1. 28-58.

Berwick, Robert C. \& Noam Chomsky. 2016. Why only us: Language and evolution. Cambridge, MA: MIT Press.

Bickel, Balthasar. 2015. Distributional Typology. In Heiko Narrog \& Bernd Heine (eds.), The Oxford handbook of linguistic analysis. Oxford: OUP.

Blake, Barry J. 1990. Relational grammar. London: Routledge.

Bloomfield, Leonard. 1933. Language. New York: H. Holt and Company.

Boeckx, Cedric. 2014. What principles and parameters got wrong. In Carme Picallo (ed.), Linguistic variation in the minimalist framework, 155-178. Oxford: OUP.

Bornkessel-Schlesewsky, Ina \& Matthias Schlesewsky. 2009. Processing syntax and morphology: A neurocognitive perspective. Oxford: OUP.

Bresnan, Joan. 2001. Lexical-functional syntax. Oxford: Blackwell.

Chomsky, Noam. 1995. Language and nature. Mind 104. 1-61.

Chomsky, Noam A. 1957. Syntactic structures. 's-Gravenhage: Mouton.

Chomsky, Noam A. 1965. Aspects of the theory of syntax. Cambridge, MA: MIT Press.

Chomsky, Noam A. 1970. Remarks on nominalization. In Roderick A Jacobs \& Peter S. Rosenbaum (eds.), Readings in English transformational grammar, 184-221. Waltham, MA: Ginn.

Chomsky, Noam A. 1981. Lectures on government and binding. Dordrecht: Foris.

Chomsky, Noam A. 1986. Knowledge of language: Its nature, origin, and use. New York: Praeger.

Chomsky, Noam A. 2005. Three factors in language design. Linguistic Inquiry 36. 1-22.

Chomsky, Noam, Ángel J. Gallego \& Dennis Ott. 2019. Generative grammar and the faculty of language: Insights, questions, and challenges. Catalan Journal of Linguistics (special issue). 229-261. https://doi.org/10.5565/rev/catjl.288.

Cinque, Guglielmo. 1999. Adverbs and functional heads: A cross-linguistic approach. New York: OUP.

Comrie, Bernard. 1999. Reference-tracking: Description and explanation. Sprachtypologie und Universalienforschung 52. 335-346.

Cristofaro, Sonia. 2009. Grammatical categories and relations: Universality vs. languagespecificity and construction-specificity. Language and Linguistics Compass 3. 441-479.

Croft, William. 2001. Radical construction grammar: Syntactic theory in typological perspective. Oxford: OUP.

Croft, William. 2003. Typology and universals. Cambridge: CUP.

Culicover, Peter W. \& Ray S. Jackendoff. 2005. Simpler syntax. Oxford: OUP.

Curtius, Georg. 1862. Philologie und Sprachwissenschaft: Antrittsvorlesung gehalten am 30. April 1862. Leipzig: Teubner.

D'Alessandro, Roberta. 2019. The achievements of Generative Syntax: a time chart and some reflections. Catalan Journal of Linguistics (special issue). 7-26. https://doi.org/10.5565/ $\mathrm{rev} / \mathrm{catj}$ l.232. 
Diessel, Holger. 2014. Demonstratives, frames of reference, and semantic universals of space. Language and Linguistics Compass 8. 116-132.

Dryer, Matthew S. 1997. Are grammatical relations universal? In Joan L. Bybee, John Haiman \& Sandra A. Thompson (eds.), Essays on language function and language type, 115-143. Amsterdam: Benjamins.

Dryer, Matthew S. 2005. Order of subject, object and verb. In Martin Haspelmath, Matthew S. Dryer, David Gil \& Bernard Comrie (eds.), The World Atlas of Language Structures, 330-333. Oxford: OUP. https://wals.info/chapter/81.

Dryer, Matthew S. 2006. Descriptive theories, explanatory theories, and basic linguistic theory. In Felix K. Ameka, Alan Dench \& Nicholas Evans (eds.), Catching language: The standing challenge of grammar writing, 207-234. Berlin: Mouton de Gruyter.

Dryer, Matthew S. 2016. Crosslinguistic categories, comparative concepts, and the Walman diminutive. Linguistic Typology 20. 305-331.

Evans, Nicholas \& Alan Dench. 2006. Introduction: Catching language. In Felix K. Ameka, Alan Dench \& Nicholas Evans (eds.), Catching language: The standing challenge of grammar writing, 1-39. Berlin: Mouton de Gruyter.

Gordon, Matthew Kelly. 2016. Phonological typology. Oxford: OUP.

Greenberg, Joseph H. 1963. Some universals of grammar with particular reference to the order of meaningful elements. In Joseph H. Greenberg (ed.), Universals of language, 73-113. Cambridge, MA: MIT Press.

Grimshaw, Jane. 1990. Argument structure. Cambridge, MA: MIT Press.

Haspelmath, Martin. 2004. Does linguistic explanation presuppose linguistic description?. Studies in Language 28. 554-579.

Haspelmath, Martin. 2008. A frequentist explanation of some universals of reflexive marking. Linguistic Discovery 6. 40-63.

Haspelmath, Martin. 2010a. Framework-free grammatical theory. In Bernd Heine \& Heiko Narrog (eds.), The Oxford handbook of linguistic analysis, 341-365. Oxford: OUP.

Haspelmath, Martin. 2010b. Comparative concepts and descriptive categories in crosslinguistic studies. Language 86. 663-687.

Haspelmath, Martin. 2011. On S, A, P, T, and R as comparative concepts for alignment typology. Linguistic Typology 15. 535-567.

Haspelmath, Martin. 2014. Comparative syntax. In Andrew Carnie, Yosuke Sato \& Dan Siddiqi (eds.), The Routledge handbook of syntax, 490-508. London: Routledge.

Haspelmath, Martin. 2018. How comparative concepts and descriptive linguistic categories are different. In Daniël Van Olmen, Tanja Mortelmans \& Frank Brisard (eds.), Aspects of linguistic variation, 83-113. Berlin: De Gruyter Mouton.

Haspelmath, Martin. 2019. Ergativity and depth of analysis. Rhema 4. 108-130.

Haspelmath, Martin. 2020a. Human linguisticality and the building blocks of languages. Frontiers in Psychology 10(3056). 1-10.

Haspelmath, Martin. 2020b. The structural uniqueness of languages and the value of comparison for description. Asian Languages and Linguistics 1. 346-366.

Hauser, Marc D., Noam Chomsky \& W. Tecumseh Fitch. 2002. The faculty of language: What is it, who has it, and how did it evolve?. Science 298(5598). 1569-1579.

Hawkins, John A. 2014. Cross-linguistic variation and efficiency. New York: OUP.

Hayes, Bruce, Robert Kirchner \& Donca Steriade (eds.). 2004. Phonetically based phonology. Cambridge: CUP. 
Holmberg, Anders, Michelle Sheehan \& Jenneke van der Wal. 2019. Movement from the double object construction is not fully symmetrical. Linguistic Inquiry 50. 677-722.

Hornstein, Norbert. 2018. Universals: Structural and substantive. Faculty of Language (blog). https://facultyoflanguage.blogspot.com/2018/02/universals-structural-and-substantive. html.

Huang, C.-T. James \& lan Roberts. 2016. Principles and parameters of universal grammar. In Ian Roberts (ed.), The Oxford handbook of universal grammar. Oxford: OUP.

Jackendoff, Ray. 2002. Foundations of language: Brain, meaning, grammar, evolution. Oxford: OUP.

Jaeger, T. Florian \& Elisabeth J. Norcliffe. 2009. The cross-linguistic study of sentence production. Language and Linguistics Compass 3. 866-887.

Joseph, John Earl. 2012. Saussure. Oxford: OUP.

Koeneman, Olaf \& Hedde Zeijlstra. 2017. Syntax. Cambridge: CUP.

Koerner, E.F.K. 1973. The importance of Techmer's “Internationale Zeitschrift für Allgemeine Sprachwissenschaft" in the development of general linguistics. Amsterdam: Benjamins.

Koptjevskaja-Tamm, Maria. 2001. Adnominal possession. In Martin Haspelmath, Ekkehard König, Wulf Oesterreicher \& Wolfgang Raible (eds.), Language typology and language universals: An international handbook, 960-970. Berlin: Mouton de Gruyter.

Krifka, Manfred. 2008. Functional similarities between bimanual coordination and topic/ comment structure. In Regine Eckardt, Gerhard Jäger \& Tonjes Veenstra (eds.), Variation, selection, development, 307-336. Berlin: Mouton de Gruyter.

Larson, Richard K. 2010. Grammar as science. Cambridge, Mass: MIT Press.

Lasnik, Howard \& Jeffrey L. Lidz. 2016. The argument from the poverty of the stimulus. In Ian Roberts (ed.), The Oxford handbook of universal grammar. Oxford: OUP.

Lazard, Gilbert. 2005. What are we typologists doing? In Zygmunt Frajzyngier, Adam Hodges \& David S. Rood (eds.), Linguistic diversity and language theories, 1-23. Amsterdam: Benjamins.

Levinson, Stephen C. \& Nicholas Evans. 2010. Time for a sea-change in linguistics: Response to comments on 'The myth of language universals'. Lingua 120. 2733-2758.

Lyons, John. 1968. Introduction to theoretical linguistics. Cambridge: CUP.

Mayr, Ernst. 1959. Darwin and the evolutionary theory in biology. In Evolution and anthropology: $A$ centennial appraisal. Washington, DC: The Anthropological Society of Washington.

Mendívil-Giró, José-Luis. 2019. How much data does linguistic theory need? On the tolerance principle of linguistic theorizing. Frontiers in Communication 3. https://doi.org/10.3389/ fcomm.2018.00062.

Mielke, Jeff. 2008. The emergence of distinctive features. Oxford: OUP.

Moravcsik, Edith A. 2011. Explaining language universals. In Jae Jung Song (ed.), The Oxford handbook of language typology, 69-89. Oxford: OUP.

Newmeyer, Frederick J. 1994. A note on Chomsky on form and function. Journal of Linguistics 30. 245-251.

Newmeyer, Frederick J. 2005. Possible and probable languages: A generative perspective on linguistic typology. Oxford: OUP.

Parry, Richard. 2020. Episteme and Techne. In Edward N. Zalta (ed.), The Stanford Encyclopedia of Philosophy. Summer 2020. Stanford: Stanford University.

Paul, Hermann. 1880. Principien der Sprachgeschichte. Halle: Niemeyer.

Pedersen, Holger. 1931. The discovery of language: Linguistic science in the nineteenth century. Cambridge, MA: Harvard University Press. 
Percival, W. Keith. 1995. The genealogy of general linguistics. In Kurt R. Jankowsky (ed.), History of linguistics 1993, 47-54. Amsterdam: Benjamins.

Pesetsky, David. 2013. Russian case morphology and the syntactic categories. Cambridge, MA: MIT Press.

Reichling, Anton. 1949. What is general linguistics?. Lingua 1. 8-24.

Rivarol, Antoine de. 1784. Discours sur l'universalité de la langue française. In Berlin: Prussian Academy of Sciences. https://en.wikipedia.org/wiki/The_Universality_of_the_French_ Language.

Roberts, Ian G. 1997. Comparative syntax. London: Arnold.

Robins, Robert H. 1964. General linguistics: An introductory survey. London: Routledge.

Round, Erich \& Greville G. Corbett. 2020. Comparability and measurement in typological science: The bright future for linguistics. To appear.

Sapir, Edward. 1921. Language: An introduction to the study of speech. New York: Harcourt, Brace \& Co.

Saussure, Ferdinand de. 1916. Cours de linguistique générale. Lausanne: Payot.

Schmidtke-Bode, Karsten, Natalia Levshina, Susanne Maria Michaelis \& Ilja A. Seržant (eds.). 2019. Explanation in typology: Diachronic sources, functional motivations and the nature of the evidence. Berlin: Language Science Press.

Schnelle, Helmut. 1974. Editorial. Theoretical Linguistics 1. 1-5.

Slobin, Dan Isaac (ed.). 1985. The cross-linguistic study of language acquisition. Hillsdale, NJ: Erlbaum.

Smirnova, Anastasia \& Ray Jackendoff. 2017. Case assignment and argument realization in nominals. Language 93. 877-911.

Song, Jae Jung. 2018. Linguistic typology. Oxford: OUP.

Vendryes, Joseph. 1921. Le langage. Paris: Renaissance du livre.

Welch, Nicholas. 2016. Propping up predicates: Adjectival predication in Tłı̨chǫ Yatıì. Glossa: $A$ Journal of General Linguistics 1(2). 1-23.

Whitney, William D. 1875. The life and growth of language. London: Routledge/Thoemmes Press. 